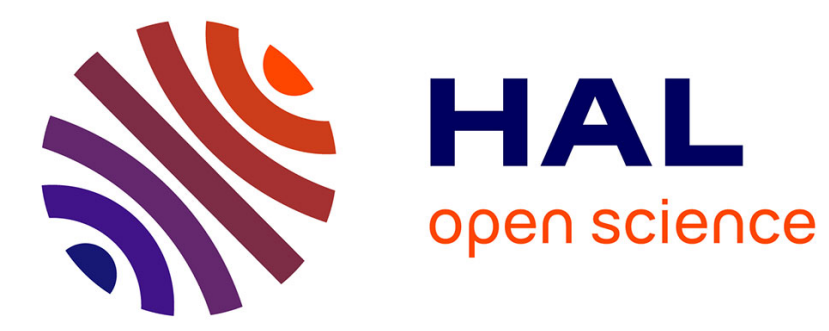

\title{
Postural control in high-level kata and kumite karatekas
}

Gérôme Gauchard, Alexis Lion, Loïc Bento, Philippe P. Perrin, Hadrien Ceyte

\section{To cite this version:}

Gérôme Gauchard, Alexis Lion, Loïc Bento, Philippe P. Perrin, Hadrien Ceyte. Postural control in high-level kata and kumite karatekas. Movement \& Sport Sciences - Science \& Motricité, 2018, 100, pp.21-26. 10.1051/sm/2017005 . hal-02003725

\section{HAL Id: hal-02003725 \\ https://hal.univ-lorraine.fr/hal-02003725}

Submitted on 1 Feb 2019

HAL is a multi-disciplinary open access archive for the deposit and dissemination of scientific research documents, whether they are published or not. The documents may come from teaching and research institutions in France or abroad, or from public or private research centers.
L'archive ouverte pluridisciplinaire HAL, est destinée au dépôt et à la diffusion de documents scientifiques de niveau recherche, publiés ou non, émanant des établissements d'enseignement et de recherche français ou étrangers, des laboratoires publics ou privés. 


\title{
Postural control in high-level kata and kumite karatekas
}

\author{
Gérome C. Gauchard ${ }^{1,2,3,}$, Alexis Lion ${ }^{2,4}$, Loïc Bento ${ }^{1}$, Philippe P. Perrin ${ }^{1,2,3}$, and Hadrien Ceyte ${ }^{1,2}$ \\ ${ }^{1}$ Université de Lorraine, UFR-STAPS - Faculty of Sport Sciences, Villers-lès-Nancy, 54603, France \\ ${ }^{2}$ Université de Lorraine, EA 3450 DevAH - Development, Adaptation and Disability, Villers-lès-Nancy, 54603, France \\ 3 LAPEM - Laboratory for Analysis of Posture, Equilibration \& Motricity, CHRU of Nancy, Vandœuvre-lès-Nancy, \\ 54500, France \\ ${ }^{4}$ Sports Medicine Research Laboratory, Luxembourg Institute of Health, 1460, Luxembourg, Luxembourg
}

Received 19 April 2016, Accepted 17 April 2017

\begin{abstract}
Postural performance may vary according to the constraints related to the practice of different martial arts. This study aimed to investigate the visual and tactile contribution in balance control: (i) between karatekas and sedentary controls; (ii) between kata and kumite specialists within the elite karatekas. Balance control in quiet stance of 23 high-level karatekas (11 kata and 12 kumite specialists) and of 24 sedentary controls was evaluated in four sensory context conditions, a combination of visual cue availability (eyes open or closed) and tactile support reliability (firm or foam surface). The results showed that karatekas had a reduced body sway and a smaller sway area compared to controls, especially in the more challenging condition, i.e. eyes closed on a foam surface. Moreover, kata karatekas tended to have a reduced body sway and a smaller sway area than kumite karatekas in all sensory conditions. The practice of karate may enhance balance control in quiet stance by optimizing the role of tactile cues and by decreasing the weighting of visual cues. Moreover, the specialization into different karateka practices may induce the implementation of specific postural strategies to solve a given balance problem.
\end{abstract}

Key words: balance control, body sway, karate, specialization

Résumé-Contrôle postural de karatekas élites spécialistes du kata et du kumite. Les performances et les stratégies posturales peuvent varier en fonction des contraintes liées à la pratique de certains arts martiaux. L'objectif de cette étude était d'analyser les contributions visuelles et tactiles sur le contrôle postural : (i) entre des pratiquants de karaté et des participants sédentaires; (ii) entre des karatékas spécialistes de kata ou de kumite. Le contrôle postural orthostatique de 23 karatékas de haut niveau (11 spécialistes de kata et 12 de kumite) et 24 participants sédentaires a été analysé dans quatre contextes sensoriels différents combinant la disponibilité des informations visuelles (yeux ouverts ou fermés) et la fiabilité des informations tactiles (supports durs ou mous). Les résultats ont montré que les karatékas présentaient des oscillations posturales de plus faible amplitude et des surfaces d'oscillation moins étendues que celles obtenues chez les participants sédentaires, en particulier dans la condition sensorielle la plus difficile, c'est-à-dire les yeux fermés sur un support mou. Par ailleurs, les spécialistes de kata tendaient à présenter de plus faibles oscillations posturales avec des surfaces d'oscillation plus réduites que celles obtenues chez les spécialistes de kumite. La pratique du karaté semblerait optimiser le rôle des informations tactiles tout en diminuant la contribution des informations visuelles dans le contrôle de la posture statique. De plus, se spécialiser dans une des pratiques du karaté influencerait la mise en place de stratégies posturales spécifiques pour résoudre un même problème postural.

Mots clés : contrôle postural, oscillation corporelle, karaté, spécialisation

\section{Introduction}

Karate, or the art of the empty hand fighting, is an ancient Japanese martial art and also the most popular one in the world, with over 10 million athletes and

\footnotetext{
*Corresponding author: gerome.gauchard@univ-lorraine.fr
}

100 million practitioners. Karate practice consists in repeated sequences of attack and defense strikes interrupted by recovery periods; it requires high-level of motor and functional abilities involving speed, strength, coordination (Blažević, Katić, \& Popović, 2006) and balance (Cesari \& Bertucco, 2008; Perrot, Moes, Deviterne, \& Perrin, 1998). The art of karate teaches three fields of 
study, which are complementary: kihon, kata and kumite (Habersetzer \& Habersetzer, 2004). Kihon concerns all the fundamental techniques of karate (fist and kick techniques and displacements) and their sequences, which are organized in repetitions of attack and defense including counter-attacks. Kata is a standardized and ritualized sequence of offensive and defensive techniques simulating virtual fighting. Kumite is score-based, time-limited fighting with punches and kicks between two opponents (Filingeri, Bianco, Zangla, Paoli, \& Palma, 2012). Balance control is a key component of the performance, especially in the martial arts, and is particularly enhanced by their practice (Filingeri et al., 2012; Perrin, Schneider, Deviterne, Perrot, \& Constantinescu, 1998; Pons van Dijk, Lenssen, Leffers, Kingma, \& Lodder, 2013; Zago et al., 2015). The main studies exploring relationships between balance control and martial arts focus on Tai Chi or grappling combat sports, such as judo (Castropil \& Arnoni, 2014; Itamar, Schwartz, \& Melzer, 2013; Li et al., 2012; Perrin et al., 1998; Perrin, Deviterne, Hugel, \& Perrot, 2002). Within striking combat sports, these relationships are rather well-known for Taekwondo (Fong \& Ng, 2012; Leong, Fu, Ng, \& Tsang, 2011; Negahban, Aryan, Mazaheri, Norasteh, \& Sanjari, 2013; Pons van Dijk et al., 2013), whereas karate has received less attention, despite the high variety of situations related to potential specializations. Most of the studies focusing on the relationships between karate and balance control were either interested in stabilometric analysis of posture coupled with a gesture or not (Cesari \& Bertucco, 2008; Del Percio et al., 2007, 2009; Juras et al., 2013; Perrot et al., 1998; Pop, Czamy, Glista, \& Skrzypiec, 2013; Vando et al., 2013) or in 3D analysis during fundamental techniques of kihon (Zago et al., 2015). Nevertheless, to our knowledge, no further studies have focused on the sensory contribution to balance control in karatekas. Indeed, the ability to select the most reliable information is a key point of the postural organization in karate, according to the mandatory postural adaptations to perform efficient offensive and defensive techniques (Filingeri et al., 2012). Furthermore, high-level competitive practice in karate requires a disciplinary specialization of the karatekas, either choosing the kumite or the kata, leading to a long-term specialization of postural control.

The aim of this study was two-fold:

- to compare in quiet stance the visual and tactile contribution to postural control in high-level karatekas compared to sedentary adults;

- to investigate the differentiated effect of kata and kumite specialties on these sensory contributions.

In agreement with Yiou and Do (2001) and their findings on the necessary complexity of the motor tasks to allow differences in experts and novices to emerge, we firstly predicted greater postural performances in karatekas than in sedentary adults, especially during the more challenging tasks, which would result in a narrower sway area and a reduced body sway. Secondly, the expertise level of kata and kumite karatekas being similar and the postural task being relatively easy to perform for highlevel athletes, we did not predict a differentiated use of visual and tactile cues for postural control according to the specialization. Nevertheless, body fixation is needed during certain phases in kata, especially during the transitional phases. These phases occur between two dynamic sequences of techniques and are characterized by clearly marked body positions. In this context, we ventured that the postural strategies could be different between kata and kumite specialties to solve the same postural problem, whatever the sensory context challenge.

\section{Methods}

\subsection{Participants}

Twenty-three high-level karatekas (6 women and 17 men, 14 years of practice) and 24 controls (8 women and $16 \mathrm{men}$ ), who did not practice sport regularly, volunteered to participate in the study. The karatekas, who were licensed at the "Fédération française de karaté et disciplines associées" or the "Fédération luxembourgeoise des arts martiaux", practiced their sport regularly at national (national champions) or international (continental and world champions) level and did not practice any other type of combat sport. The selection criteria were: - to be or have been an elite karate athlete (registered on the national list of elite athletes and/or to be a member of the national team);

- to have a minimum of a black belt 1st dan;

- to have passed a national podium (cup or championship).

The karate group was composed of 11 kata ( 3 women and 8 men; 4 national champions, 1 winner of the French Cup) and 12 kumite (3women and 9 men; 6 national champions, 3 European champions, 1 World champion) specialists. Kata or kumite specialists almost never practice the other specialty; indeed, according to their trainers, only 1 or $2 \%$ of their annual training time was dedicated to the other specialty. No participant had a history of psychiatric or neurological disorders, or showed any orthopedic disorders either of the trunk or the lower limbs that could affect postural performance. The experimental protocol followed the recommendations of the Declaration of Helsinki. All the participants gave their written informed consent prior to the study.

\subsection{Apparatus}

All participants were tested on a force platform $\left(\right.$ Satel ${ }^{\circledR}$, Blagnac, France) mounted on three strain-gauge force transducers, which measured the vertical component of the force and allowed the calculation of the center of foot pressure $(\mathrm{CoP})$ displacement in time in a horizontal plane (recording time: $25.6 \mathrm{~s}$, acquisition frequency: $40 \mathrm{~Hz}$ ). This technological device is used specifically for static postural evaluation. The classical procedure eliminates $10 \%$ of the extreme points in order to suppress postural sway values that could have been due to quasi voluntary movements not indicative of the amount of body sway. 


\subsection{Measurements}

Posturographic signal can be described in terms of two postural factors: postural accuracy and steadiness (Cavanaugh, Guskiewicz, \& Stergiou, 2005; Murray, Seireg, \& Sepic, 1975). Postural accuracy is quantified from the measurement of the sway area of $\mathrm{CoP}\left(\mathrm{in} \mathrm{mm}^{2}\right)$. A reduced sway area value corresponds to greater stance precision. Steadiness, i.e. the ability to stand as motionless as possible, is measured using body sway (in mm). Increased values of body sway correspond to reduced steadiness, i.e. increased postural mobility.

\subsection{Procedure}

For each recording, the participant was asked to stand barefoot and upright on the platform, feet $30^{\circ}$ apart, remaining as stable as possible and breathing normally with arms along the sides. The task was to maintain an upright stance, as stable as possible, in four sensory context conditions, combining visual cues (eyes open or closed) and reliability of tactile support (firm or foam surface). Basic measurements of the participant's postural performance were done with eyes open, i.e. looking at a dot at eye level, 2 meters in front of them, and on firm support. To suppress the visual cues, the participants were asked to close their eyes and, to provide unreliable tactile cues under their feet, a $5 \mathrm{~cm}-$ thick foam support (density: $50 \mathrm{~kg} \cdot \mathrm{m}^{-3}$-Airex ${ }^{\circledR}$ Balance, Sins, Switzerland) was placed on the platform. These four sensory context conditions were repeated three times. All conditions were performed in random order by each participant. Participants were not given any information about their postural performance.

\subsection{Statistical analysis}

Gender was compared by $\chi^{2}$ test or Fisher's exact tests according to the condition of application of the tests. Normal distribution of quantitative data, which was expressed as mean with standard errors (SE), was verified using the Shapiro-Wilk test. Student $t$-test was used to compare the age and the Body Mass Index (BMI) between the different groups. For each postural parameters (sway area and body sway), the mean result of the trials was calculated. Firstly, to compare the visual and tactile contribution on the postural control in high-level karatekas and sedentary adults, 2 population (karatekas; controls $) \times 2$ visual context (eyes open; eyes closed $) \times 2$ tactile context (firm support; foam support) repeated measures ANOVAs were done on sway area and body sways. Secondly, to analyze the effect of specialties of karate practice, 2 karate specialization (kumite vs. kata) $\times 2$ visual context (eyes open; eyes closed) $\times 2$ tactile context (firm support; foam support) repeated measures ANOVAs were applied on sway area and body sways. The Tukey's HSD test was used for post hoc comparisons. A $0.05 p$-level of significance was set. Borderline significance was defined at a level of $p<0.10$
Table 1. Statistical comparisons between karatekas and controls for age and body mass index - BMI - (mean with standard errors $-\mathrm{SE}-$ ).

\begin{tabular}{|c|c|c|c|}
\hline & $\begin{array}{l}\text { Karatekas } \\
(n=23)\end{array}$ & $\begin{array}{l}\text { Controls } \\
(n=24)\end{array}$ & $\begin{array}{l}\text { Intergroup } \\
\text { comparisons }\end{array}$ \\
\hline & Mean (SE) & Mean (SE) & $t$-value, $p$-value \\
\hline & $22.13(1.30)$ & $24.53(0.79)$ & $t=-1.56, p=0.12$ \\
\hline BMI $\left(\mathrm{kg} \cdot \mathrm{m}^{-2}\right)$ & $21.53(0.43)$ & $22.24(0.45)$ & $t=-1.15, p=0.26$ \\
\hline
\end{tabular}

Table 2. Statistical comparisons between kata and kumite karatekas for age and body mass index - BMI - (mean with standard errors $-\mathrm{SE}-$ ).

\begin{tabular}{|c|c|c|c|}
\hline & $\begin{array}{l}\text { Kata } \\
(n=11)\end{array}$ & $\begin{array}{l}\text { Kumite } \\
(n=12)\end{array}$ & $\begin{array}{l}\text { Intergroup } \\
\text { comparisons }\end{array}$ \\
\hline & Mean (SE) & Mean (SE) & $t$-value, $p$-value \\
\hline$\overline{\text { Age }}$ & $22.71(1.90)$ & $21.61(1.84)$ & $t=-0.46, p=0.68$ \\
\hline BMI $\left(\mathrm{kg} \cdot \mathrm{m}^{-2}\right)$ & $21.88(0.54)$ & $21.22(0.66)$ & $t=-0.76, p=0.46$ \\
\hline
\end{tabular}

\section{Results}

Concerning participants, no statistically significant difference was observed between karatekas and controls for gender $\left(\chi^{2}=0.29, p=0.59\right)$, age or BMI (Tab. 1$)$. In addition, no statistically significant difference was observed between kata and kumite karatekas for the same parameters (gender: Fisher's exact test, $p=0.99$; see Tab. 2 for age and BMI).

Regarding the effect of karate practice, the first repeated measures ANOVA (Fig. 1) showed a main effect of the population $\left[F_{(1,45)}=11.32, p<0.01\right]$ for sway area, suggesting that karatekas swayed in a smaller ground area than controls $\left(423.96 \mathrm{~mm}^{2} \pm 33.80\right.$ vs. $583.10 \mathrm{~mm}^{2} \pm 33.09$, $p<0.01)$. In addition, an interaction population $\times$ tactile context was observed $\left[F_{(1,45)}=5.32, p<0.05\right]$. Indeed, compared to karatekas, sway area in sedentary controls was significantly higher with the tactile unreliability (controls: $924.42 \mathrm{~mm}^{2} \pm 53.8$; karatekas: $684.22 \mathrm{~mm}^{2}$ $\pm 55.0 ; p<0.001)$. The interaction population $\times$ visual context showed an increase in sway area $\left[F_{(1,45)}=15.60\right.$, $p<0.001]$ and body sway $\left[F_{(1,45)}=13,47, p<0.001\right]$, which were significantly more important in controls than in karatekas (sway area: $581.63 \mathrm{~mm}^{2} \pm 53.79$ vs. $869.58 \mathrm{~mm}^{2}$ \pm 52.65 , respectively, $p<0.001$; body sway: $617.84 \mathrm{~mm}$ \pm 35.63 vs. $741.57 \mathrm{~mm} \pm 34.88$, respectively, $p<0.05)$ when the visual cues were unavailable. The three-way interaction of population $\times$ tactile context $\times$ visual context showed that the interaction effects of the sensory context conditions previously presented was dependent on the population for sway area $\left[F_{(1,45)}=11.84, p<0.01\right]$ (Fig. 1A) and for body sway $\left[F_{(1,45)}=5.33, p<0.05\right]$ (Fig. 1B). Post hoc comparisons showed that in both populations the sway area and body sway were significantly higher on foam support with eyes closed than that observed in eyes open on the same support $(p<0.001)$. Conversely, on firm support, the body sway was significantly higher in eyes closed than that observed in 


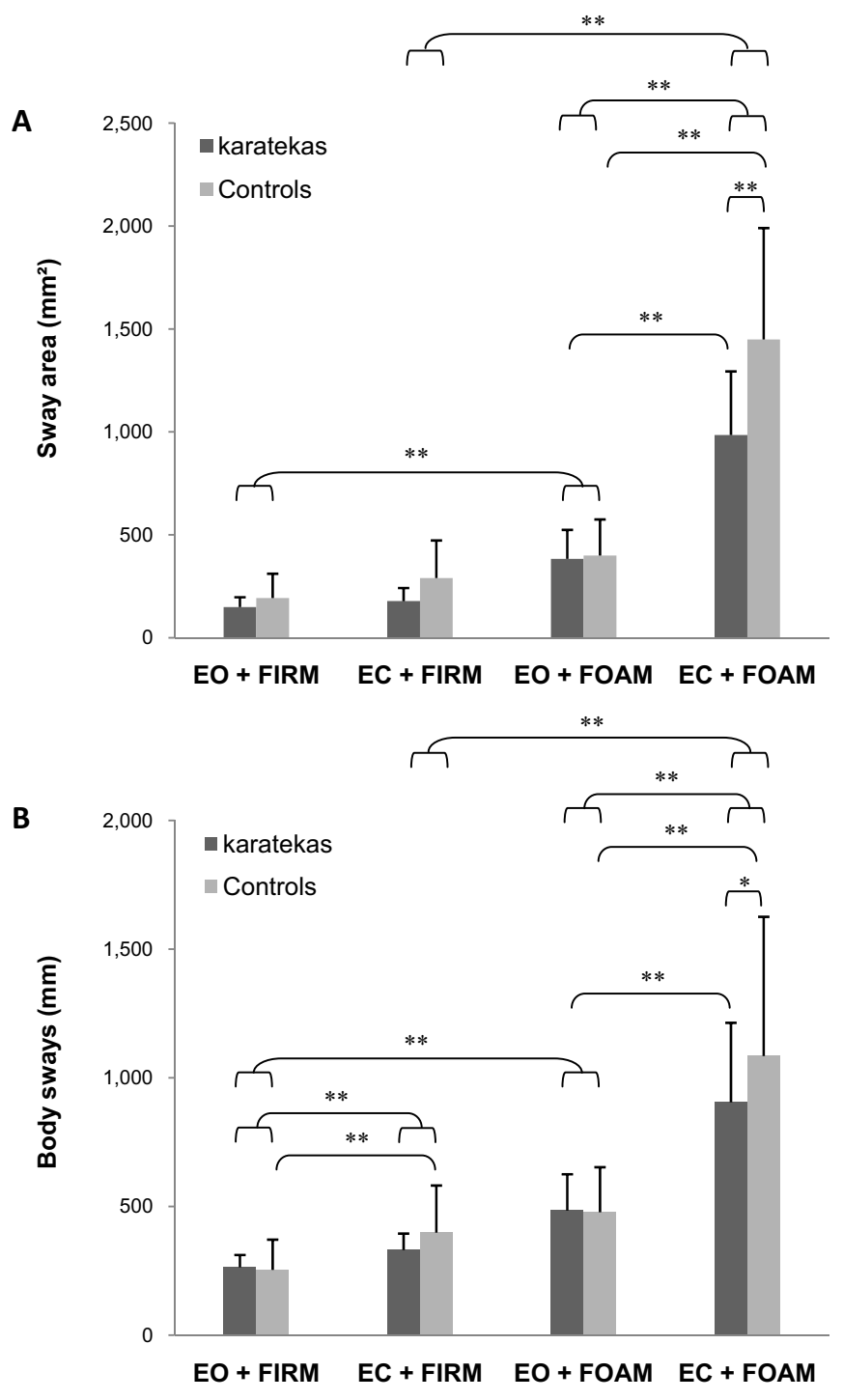

Fig. 1. Mean values with standard errors of sway area (Panel A) and body sway (Panel B) parameters in eyes open (EO) and in eyes closed (EC) conditions on firm (FIRM) and foam (FOAM) supports observed in karatekas (dark grey bars) and controls (light grey bars). Post-hoc comparisons: ${ }^{*} p<0.05,{ }^{* *} p<0.001$.

eyes open only in controls $(p<0.001)$. In addition, the results showed higher sway area $(p<0.001)$ and higher body sway $(p<0.05)$ in controls having eyes closed on foam support compared to that of karatekas.

Concerning the effect of karate specialization on the sensory contribution to posture (Tab. 3), the second repeated measures ANOVA showed that the main effect of karate specialization tented to be significant for sway area $\left[F_{(1,21)}=3.45, \quad p=0.07\right]$, suggesting that the kumite karatekas may have a larger sway area than the kata karatekas, and with regards to body sway $\left[F_{(1,21)}=3.80\right.$, $p=0.06]$, the results also suggested a higher amount of body sway in kumite karatekas. No two-way interaction was observed with the karate specialization. The threeway interaction of karate specialization $\times$ visual context $\times$ tactile context failed to be significant for sway area and for body sway.
Table 3. Mean values with standard errors (SE) of sway area and body sway observed in kata and kumite karatekas in eyes open (EO) and closed (EC) conditions on firm (FIRM) and foam (FOAM) supports.

\begin{tabular}{|c|c|c|c|}
\hline \multirow[t]{2}{*}{ Parameters } & \multirow[t]{2}{*}{ Conditions } & $\begin{array}{l}\text { Kata } \\
(n=11)\end{array}$ & $\begin{array}{l}\text { Kumite } \\
(n=12)\end{array}$ \\
\hline & & Mean (SE) & Mean (SE) \\
\hline \multirow[t]{4}{*}{ Sway area $\left(\mathrm{mm}^{2}\right)$} & $\mathrm{EO}+\mathrm{FIRM}$ & $135(11)$ & $176(14)$ \\
\hline & $\mathrm{EC}+\mathrm{FIRM}$ & $139(14)$ & $200(20)$ \\
\hline & $\mathrm{EO}+\mathrm{FOAM}$ & $351(26)$ & $413(51)$ \\
\hline & $\mathrm{EC}+\mathrm{FOAM}$ & $898(79)$ & $1064(97)$ \\
\hline \multirow[t]{4}{*}{ Body sways (mm) } & $\mathrm{EO}+\mathrm{FIRM}$ & $224(16)$ & $300(19)$ \\
\hline & $\mathrm{EC}+\mathrm{FIRM}$ & $287(23)$ & $371(27)$ \\
\hline & $\mathrm{EO}+\mathrm{FOAM}$ & $439(19)$ & $526(38)$ \\
\hline & $\mathrm{EC}+\mathrm{FOAM}$ & $860(61)$ & $945(64)$ \\
\hline
\end{tabular}

\section{Discussion}

The rationale of this study was to investigate the visual and tactile contributions on postural control:

- between high-level karatekas and sedentary participants;

- between karateka specialists in kata or kumite.

Our results agreed with previous observations (Del Percio et al., 2007, 2009) that karate practice does not influence orthostatic postural control during the easiest postural challenge (with eyes open on firm support). However in the more difficult postural challenge (with eyes closed on foam support), postural control deteriorates largely in both populations, but karatekas were less affected than sedentary participants confirming our first hypothesis. Indeed, they showed smaller sway area and reduced body sway. Overall, disrupting sensory cues induces an increase in body sway; nevertheless, the unavailability of visual anchorage was better handled by karatekas especially when tactile cues were unreliable. Such environmental context would lead to an increased body sway in sedentary participants and probably also to a larger sway surface. Karate practice may allow a reduction of this postural degradation due to a greater control of steadiness and a greater stance precision (Bajorek et al., 2011; Perrot et al., 1998; Pop et al., 2013), despite the weakness of sensory contexts. In other words, in karatekas, postural control would not depend exclusively on visual cues; tactile cues may be used to help balance control in function of its degree of reliability. This is consistent with the requirements of barefooted practices developing the plantar tactile sense, its role being essential to an optimal motor coordination for movement but also for stance control (Dietz, Horstmann, \& Berger, 1989). The differences of postural performances between karatekas and sedentary participants can be also due to a better multi-sensory contribution, as it was proposed for other sports (Kiers, van Dieen, Dekkers, Wittink, \& Vanhees, 2013; Lion, Gokeler, \& Gauchard, 2016). Moreover, standing barefooted on a foam surface is a known situation for karatekas as they train regularly on mats in the dojo. Even if the foam support (thickness: 
$50 \mathrm{~mm}$; density: $50 \mathrm{~kg} \cdot \mathrm{m}^{-3}$ ) used here did not completely have the same specifications than dojo mats (thickness: 20-25 mm; density: approximately 200-300 $\mathrm{kg} \cdot \mathrm{m}^{-3}$; for maximum footing and stability), the habituation phenomenon to a foam surface should not be ruled out.

The outcome from the comparison of karate specialties seems to concur with our hypotheses. Indeed, it seems that visual and tactile contributions to postural control are comparable. Nevertheless, it seems that the oscillatory strategies are different between kata and kumite karatekas, the data tending to show a narrower sway area and reduced body sway for kata karatekas compared to kumite karatekas. It does not suggest that kata karatekas have greater absolute postural performances, because kumite karatekas might not be in an instable stance. We suggest that this is rather the expression of different postural strategies to perform quiet stance according to the competitive specialization of karatekas. Although our results are close to significant, they should be interpreted with caution due to a relatively low number of high-level karatekas, which were furthermore split into two subgroups according to their competitive specialization (kata vs. kumite). The increase in karateka numbers in each group should provide a move from borderline significance towards statistical significance and so considering a twoway interaction with competitive specialization. Even though kata and kumite are both recognized as soliciting dynamic balance control mechanisms, kata necessitates the management of known and fixed transitional phases in the context of predictable situations, whereas kumite necessitates the management of transitional phases in the context of unpredictable movement situations. In kata, the frequent changes of direction and the large number of technical positions performed represent a challenge to the postural control and, among all the evaluation criteria, balance mastering is a key determinant of the performance. In competition, kata karatekas are penalized if a loss of balance during the execution of the techniques is noted; mastering static balance, both at global and segmental levels (Bouisset \& Do, 2008), is thus an additional constraint inherent to kata performance, especially during the fixed phases of kata, giving a need for a decrease in corporal mobility and an increase in postural accuracy. Here, the feet position on the platform during our postural task is similar to Musubi-dachi, which is the formal respectful bow where no motion is tolerated in kata competition. Mastering this position may be characterized by body sway weakness in a small sway area suggesting an accurate postural control as suggested by Filingeri et al. (2012). Conversely, displacements during this formal respectful posture are not detrimental in kumite competition. Our results suggest that, to perform the orthostatic postural task, the specific requirements of competitive specialization could influence the postural strategy, which would be characterized by a larger amount of body sway in a large sway area in kumite karatekas that might indicate an active search of sensory information necessary for efficient motor behavior in their practice context. This study focused on what appeared to be one of the fundamental differences in their motor skills, i.e. the necessary postural accuracy and steadiness in the case of kata, a next step could be to set up a more dynamic approach of balance control due to the movement sequences which have different purposes. As a reminder, kumite (a score-based, time-limited fight between two opponents) represents the maximal expression of dynamism in karate performance (Roschel et al., 2009). To be assigned a point, kumite karatekas are required to perform striking techniques to specific target areas (head, trunk and back) as fast and as powerful as possible. Fighting against a "real" opponent makes this performance extremely demanding in terms of ability to readapt their corporal posture quickly, as this is essential to perform effective offensive and defensive techniques. Thus, kumite karatekas should be able to coordinate the whole-body movements with very fast responses to unexpected offensive strategies of the opponent. A plausible hypothesis could be that balance control mechanisms would be of both reactional and anticipatory nature in the context of kumite karatekas, whereas the art of kata rather purely involves anticipatory mechanisms due to the simulation of a fight against virtual opponents. Directly in line with this point, the predictable nature of the task and the related sensory mechanisms could be studied. Indeed kata is performed in a predictable, stable sensory context whereas kumite is performed in an unpredictable, fluctuating sensory context. With this in mind, performing postural analysis during dynamic tasks, by varying the degree of predictability, could highlight the differences in balance control between kata and kumite specialists.

In conclusion, to understand postural performances, the own specificities of the individuals must be decrypted as well as their interactions with the environment, especially the sensory contribution, in which the postural evaluation occurs. Through classical postural parameters, i.e. sway area and body sway, we have shown that long-term karate practice enhances the balance control in quiet stance by optimizing the role of tactile cues and by decreasing the contribution of visual cues. Furthermore, the technical specificities related to kata practice and its requirement to actively search for permanent ground anchorage tend to lead to a more accurate postural control than kumite karatekas. Further studies are required to investigate, whether kumite practice is more demanding in terms of dynamic balance control, due to the induced active search of sensory cues in the environment which are consistent with the unpredictable situations during combat.

Acknowledgments. We are sincerely grateful to Mrs. Daniela Arcone for manuscript revision and to two anonymous reviewers for their helpful comments on an earlier version of the manuscript.

\section{Conflicts of interest}

The authors declare that they have no conflicts of interest in relation to this article. 


\section{References}

Bajorek, W., Czarny, P., Król, M., Rzepko, G., Sobo, A., \& Litwiniuk, A. (2011). Assessment of postural stability in traditional karate contestants. Journal of Combat Sports and Martial Arts, 1/2, 2.

Blažević, S., Katić, R., \& Popović, D. (2006). The effect of motor abilities on karate performance. Collegium Antropologium, 30/2, 327-333.

Bouisset, S., \& Do, M.-C. (2008). Posture, dynamic stability, and voluntary movement. Clinical Neurophysiology, 38/6, 345362.

Castropil, W., \& Arnoni, C. (2014). Postural patterns and adaptations in judo athletes. Archives of Budo, 10, 23-28.

Cavanaugh, J.T., Guskiewicz, K.M., \& Stergiou, N. (2005). A nonlinear dynamic approach for evaluating postural control: new directions for the management of sport-related cerebral concussion. Sports Medicine, 35/11, 935-950.

Cesari, P., \& Bertucco, M. (2008). Coupling between punch efficacy and body stability for elite karate. Journal of Science and Medicine in Sport, 11/3, 353-356.

Del Percio, C., Brancucci, A., Bergami, F., Marzano, N., Fiore, A., Di Ciolo, E., et al. (2007). Cortical alpha rhythms are correlated with body sway during quiet open-eyes standing in athletes: a high-resolution EEG study. NeuroImage, 36/3, 822-829.

Del Percio, C., Babiloni, C., Marzano, N., Iacoboni, M., Infarinato, F., Vecchio, F., Lizio, R., Aschieri, P., Fiore, A., Toràn, G., Gallamini, M., Baratto, M., \& Eusebi, F. (2009). "Neural efficiency" of athletes' brain for upright standing: A high-resolution EEG study. Brain Research Bulletin, 79/3, 190-200.

Dietz, V., Horstmann, G., \& Berger, W. (1989). Interlimb coordination of leg-muscle activation during perturbation of stance in humans. Journal of Neurophysiology, 62/3, 680-693.

Filingeri, D., Bianco, A., Zangla, D., Paoli, A., \& Palma, A. (2012). Is karate effective in improving postural control? Archives of Budo, 8, 203-206.

Fong, S.S., \& Ng, G.Y. (2012). Sensory integration and standing balance in adolescent taekwondo practitioners. Pediatric Exercise Science, 24/1, 142-151.

Habersetzer, G., \& Habersetzer, R. (2004). Encyclopédie des arts martiaux de l'Extrême-Orient : technique, historique, biographique et culturelle. Paris: Editions Amphora.

Itamar, N., Schwartz, D., \& Melzer, I. (2013). Postural control: differences between youth judokas and swimmers. Journal of Sports Medicine and Physical Fitness, 53/5, 483-489.

Juras, G., Rzepko, M., Krol, P., Czarny, W., Bajorek, W., Slomka, K., \& Sobota, G. (2013). The effect of expertise in karate on postural control in quiet standing. Archives of Budo, 9/3, 205-209.

Kiers, H., van Dieen, J., Dekkers, H., Wittink, H., \& Vanhees, L. (2013). A systematic review of the relationship between physical activities in sports or daily life and postural sway in upright stance. Sports Medicine, 43/11, 1171-1189.
Leong, H.-T., Fu, S.N., Ng, G.Y., \& Tsang, W.W. (2011). Lowlevel Taekwondo practitioners have better somatosensory organisation in standing balance than sedentary people. European Journal of Applied Physiology, 111/8, 17871793.

Li, F., Harmer, P., Fitzgerald, K., Eckstrom, E., Stock, R., Galver, J., Maddalozzo, G., \& Batya, S.S. (2012). Tai chi and postural stability in patients with Parkinson's disease. New England Journal of Medicine, 366/6, 511-519.

Lion, A., Gokeler, A., \& Gauchard, G.C. (2016). Sport et contrôle postural chez l'adulte. In T. Paillard (Ed.), Posture, équilibre et mouvement (pp. 201-211). Brussels: De Boeck.

Murray, M.P., Seireg, A.A., \& Sepic, S.B. (1975). Normal postural stability and steadiness: quantitative assessment. Journal of Bone and Joint Surgery, 57A/4, 510-516.

Negahban, H., Aryan, N., Mazaheri, M., Norasteh, A.A., \& Sanjari, M.A. (2013). Effect of expertise in shooting and Taekwondo on bipedal and unipedal postural control isolated or concurrent with a reaction-time task. Gait $\&$ Posture, $38 /$ 2, 226-230.

Perrin, P., Schneider, D., Deviterne, D., Perrot, C., \& Constantinescu, L. (1998). Training improves the adaptation to changing visual conditions in maintaining human posture control in a test of sinusoidal oscillation of the support. Neuroscience Letters, 245/3, 155-158.

Perrin, P., Deviterne, D., Hugel, F., \& Perrot, C. (2002). Judo, better than dance, develops sensorimotor adaptabilities

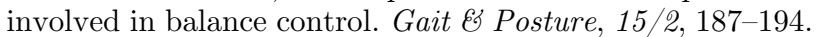

Perrot, C., Moes, R., Deviterne, D., \& Perrin, P. (1998). Postural adaptations during specific combative sport movements. Science 83 Sports, 2/13, 64-74.

Pons van Dijk, G., Lenssen, A., Leffers, P., Kingma, H., \& Lodder, J. (2013). Taekwondo training improves balance in volunteers over 40. Frontiers in Aging Neuroscience, $5,10$.

Pop, T., Czamy, W., Glista, J., \& Skrzypiec, M. (2013). Influence of traditional karate training on the stability and symmetry of the load on lower limbs. Archives of Budo, 9/1, 39-49.

Roschel, H., Batista, M., Monteiro, R., Bertuzzi, R.C., Barroso, R., Loturco, I., Ugrinowitsch, C., Tricoli, V., \& Franchini, E. (2009). Association between neuromuscular tests and kumite performance on the Brazilian Karate National Team. Journal of Sports Science and Medicine, 8/CSSI3, 20.

Vando, S., Filingeri, D., Maurino, L., Chaabène, H., Bianco, A., Salernitano, G., Foti, C., \& Padulo, J. (2013). Postural adaptations in preadolescent karate athletes due to a one week karate training camp. Journal of Human Kinetics, 38, $45-52$.

Yiou, E., \& Do, M.-C. (2001). In a complex sequential movement, what component of the motor program is improved with intensive practice, sequence timing or ensemble motor learning. Experimental Brain Research, 137/2, 197-204.

Zago, M., Mapelli, A., Shirai, Y.F., Ciprandi, D., Lovecchio, N., Galvani, C., \& Sforza, C. (2015). Dynamic balance in elite karateka. Journal of Electromyography $\&$ Kinesiology, 25/6, 894-900.

Cite this article as: Gauchard GC, Lion A, Bento L, Perrin PP, \& Ceyte H (2017) Postural control in high-level kata and kumite karatekas. Mov Sport Sci/Sci Mot, DOI: 10.1051/sm/2017005 